(2) Open Access Full Text Article

\title{
Preparation and clinical evaluation of nano- transferosomes for treatment of erectile dysfunction
}

This article was published in the following Dove Press journal:

Drug Design, Development and Therapy

29 April 2015

Number of times this article has been viewed

\author{
Maha Fadel M Ali' \\ Heba F Salem ${ }^{2}$ \\ Hany F Abdelmohsen ${ }^{3}$ \\ Sameh K Attia ${ }^{4}$ \\ 'Pharmaceutical Technology Unit, \\ Medical Applications of Lasers \\ Department, National Institute \\ of Laser Enhanced Science, \\ Cairo University, Cairo, Egypt; \\ 2Pharmaceutics and Industrial \\ Pharmacy Department, ${ }^{3}$ Clinical \\ Pharmacy Department, Faculty \\ of Pharmacy, Beni-Suef University, \\ Beni-Suef, Egypt; ${ }^{4}$ Dermatology \\ and Andrology Department, \\ Faculty of Medicine, Minia \\ University, Minia, Egypt
}

Objective: The goal of the present study was to formulate topical nanocarriers of the low-cost vasodilator, papaverine hydrochloride $(\mathrm{PH})$, as an alternative to the painful penile injections. The injections are used for both diagnosis and treatment of erectile dysfunction. Transdermal nano-transferosome $(\mathrm{T})$, the ultraflexible nanoliposome, was used as a nanocarrier to enhance the penetration of the papaverine to the penis.

Methods: Different nano formulas were prepared and characterized for their encapsulation efficiency, particle size, zeta potential, and cumulative drug release. The formula acquired the best characteristics was incorporated into $2 \%(\mathrm{w} / \mathrm{v})$ hydroxypropyl methylcellulose hydrogel base. The gel containing transferosomal papaverine hydrochloride $(\mathrm{PH})$ and that containing free PH were clinically compared using color flow Doppler measurements.

Results: The results revealed that transferosome 3 (T3) had the highest entrapment efficiency approaching $72 \%$, low particle size of $220 \mathrm{~nm}$, and zeta potential of $-33.4 \mathrm{mV}$. The formula released $73 \%$ of its initial drug content within 2 hours. The clinical evaluation showed the increase in the cavernous artery diameter from $0.53 \mathrm{~mm}$ to $0.78 \mathrm{~mm}$ and the increase in the peak systolic flow velocity from $5.95 \mathrm{~cm} / \mathrm{second}$ to $12.2 \mathrm{~cm} / \mathrm{second}$, both of which were found to be significant at $P<0.05$.

Conclusion: It is evident from the study that the transferosomes can be used as a carrier of papaverine hydrochloride for both diagnosis and treatment of the erectile dysfunction. This new strategy could be used successfully in the treatment of erectile dysfunction and in male impotency.

Keywords: transferosomes, Color Doppler, transdermal delivery, papaverine hydrochloride

\section{Introduction}

Erectile dysfunction (ED) is a common disorder affecting millions of men that can have a great negative impact on their lives. Many options are available for the treatment of ED. According to the European Association of Urology guidelines on ED, the first-line therapy includes oral medications such as sildenafil, tadalafil, and vardenafil. ${ }^{1}$ The intracavernosal injections and intraurethral therapy are considered as second-line therapies; however, high dropout rates have been frequently reported due to expensive therapy, pain on the injection site, prolonged erections, and priapism. ${ }^{1}$ Up to $50 \%$ of men who begin intracavernous therapy eventually discontinue treatment. The discomfort and lack of spontaneity involved with injections have been cited as reasons for discontinuation. Alternative forms of administration of vasoactive and vasodilatory substances are being investigated. ${ }^{2}$ Topical therapy has the potential to become a first-line treatment for ED because it acts locally at the penile level, thus
Correspondence: Heba F Salem Pharmaceutics and Industrial Pharmacy Department, Faculty of Pharmacy, Beni-Suef University, El Shahid Shehata Ahmed Hijaz St, Beni-Suef, Egypt Tel +20 I0 0194438 I

Email heba_salem2004@yahoo.co.uk 
lacking any systemic effect, and is easy to use. ${ }^{3}$ However, crossing the barrier caused by the penile skin and tunica albuginea, the thick sheath surrounding the corporal bodies, has reduced the efficacy of the drugs used topically. Topical agents remain a very attractive option with a potential to become the preferred first-line treatment if an effective delivery system was found. ${ }^{3}$

Vesicular systems have been widely used as surrogate vehicles for topical and transdermal drug delivery. Their benefits in enhancing drug permeation have been well established. ${ }^{4}$ Transferosomes offer a multilateral delivery concept for improving the stability as well as the potential to be used with a wide range of active compounds. They have ultraflexible bilayer membranes which causes vesicles to be highly deformable, such that they can squeeze through narrow pores in the stratum corneum (one-tenth of their own diameter) under nonocclusive conditions. ${ }^{4}$

The objective of this study was to deliver the vasoactive drug papaverine hydrochloride $(\mathrm{PH})$ topically rather than by injection. Nano-transferosomes were the platform for transdermal administration of the drug for the treatment of ED. Clinical evaluation of the transferosomal gel was carried out using color flow Doppler, vital signs, and clinical erections measurements. The clinical evaluation was also investigated to show the possible side effects if found.

\section{Materials and methods Materials}

Soybean phosphatidylcholine (lecithin), cholesterol, sodium deoxycholate (SDC), sorbitan monostearate (span 60), brij 35, PH powder, hydroxypropyl methylcellulose (HPMC; grade K4M) and Triton X-100 were purchased from SigmaAldrich Co., St Louis, MO, USA. Chloroform, absolute ethanol, disodium hydrogen orthophosphate $\left(\mathrm{Na}_{2} \mathrm{HPO}_{4}\right)$ and potassium dihydrogen orthophosphate $\left(\mathrm{KH}_{2} \mathrm{PO}_{4}\right)$ were purchased from El Nasr Pharmaceutical Chemicals, Abu
Zaabal, Egypt. Methyl paraben sodium and propyl paraben sodium (United States Pharmacopeia (USP) 25) were purchased from Normest Company for Scientific Development 10th of Ramadan city, Egypt. All materials used were of the analytical grade. Phosphate buffer solution (PBS, pH 5.5) was prepared using both potassium dihydrogen orthophosphate and disodium hydrogen orthophosphate.

\section{Preparation of the transferosomes encapsulating $\mathrm{PH}$}

Different transferosomal formulations containing lecithin, cholesterol, and three types of edge activators at different weight ratios (Table 1) were prepared using thin-film hydration technique. Soybean phosphatidylcholine and cholesterol were dissolved in a small quantity of a mixture of two organic solvents (chloroform:ethanol) at (1:1) v/v ratio. A very thin film of dry lipids was formed on the inner surface of the flask using rotary evaporator type Hei-VAP manufactured by Heidolph Instruments $\mathrm{GmbH} \&$ Co.KG, Schwabach, Germany. The deposited lipid film was hydrated with PH solution $(10 \mathrm{~mL}, 30 \mathrm{mg} / \mathrm{mL})$ in PBS (pH 5.5) by rotation at $90 \mathrm{rpm}$ for $1 \mathrm{~h}$. The resulting vesicles were kept for $4 \mathrm{~h}$ at ambient temperature to form large multilamellar vesicles. The transferosomal suspension was sonicated in ultrasonic water bath (model $275 \mathrm{~T}$ manufactured by Crest Ultrasonics, Trenton, NJ, USA) for 15 minutes to achieve smaller vesicles. The suspension was kept at $4^{\circ} \mathrm{C}$ overnight before usage. Unencapsulated $\mathrm{PH}$ was removed by gel chromatography technique using sephadex-G 75 gel column (Pharmacia Chemicals, Uppsala, Sweden). PBS (0.1 M, $\mathrm{pH}$ 5.5) was used for elution. The transferosomal vesicles were eluted from the column according to their sizes. Free papaverine hydrochloride (FPH) was retained in the column and separated from the vesicles. The resulting dispersion was used for the further characterization. ${ }^{5}$ The entire procedure was carried out under aseptic conditions using a laminar air

Table I Composition of the transferosomal vesicles prepared by thin-film hydration method

\begin{tabular}{|c|c|c|c|c|c|}
\hline Formula number & Lecithin (mg) & Cholesterol (mg) & SDC (mg) & Span $60(\mathrm{mg})$ & Brij 35 (mg) \\
\hline TI & 50 & 30 & 50 & - & - \\
\hline T2 & 50 & 30 & 25 & - & - \\
\hline T3 & 50 & 30 & 100 & - & - \\
\hline T4 & 50 & 30 & - & 50 & - \\
\hline T5 & 50 & 30 & - & 25 & - \\
\hline T6 & 50 & 30 & - & 100 & - \\
\hline T7 & 50 & 30 & - & - & 50 \\
\hline T8 & 50 & 30 & - & - & 25 \\
\hline T9 & 50 & 30 & - & - & 100 \\
\hline
\end{tabular}

Note: -Indicates that the corresponding surfactant was not incorporated in the corresponding formula. Abbreviations: SDC, sodium deoxycholate; T, transferosome. 
flow hood (horizontal laminar flow hood, BZ Series, model BZ-3SSRX; Germfree, Ormond Beach, FL, USA).

\section{Characterizations of transferosomes Determination of entrapment efficiency}

Percentage entrapment efficiency (EE\%) was evaluated by the centrifuge method. Two milliliters of each freshly prepared sample were centrifugated at 10,000 rpm for 40 minutes using high-speed refrigerated centrifuge, type 3-30K, manufactured by Sigma, Wem, UK. The clear supernatant was used for the determination of the unentrapped drug while the precipitated vesicles were digested using Triton X-100 (2 mL, 1\% v/v), which is diluted in PBS ( $\mathrm{pH} 5.5)$ to release the drug content and filtered using polycarbonate membrane filter $(0.2 \mu \mathrm{m})$ purchased from Whatman International Ltd, Springfield Mill, England. The clear solution was measured for entrapped $\mathrm{PH}$ using a UV spectrophotometer (UV-VIS double-beam spectrophotometer type V-530 manufactured by JASCO International Co. Ltd., Hachioji, Tokyo, Japan) at $\lambda=254 \mathrm{~nm} .^{4-6}$

$\mathrm{EE} \%=($ Entrapped drug amount $/$ Total drug amount $) \times 100$

\section{Particle size and zeta potential measurements}

The particle size distribution of the transferosomes was measured by Malvern Zetasizer (Nano ZS) version 6.12 manufactured by Malvern Instruments, Malvern, UK. Freshly prepared transferosomal suspension $(100 \mu \mathrm{L})$ was diluted with deionized water $(900 \mu \mathrm{L})$. The diluted transferosome suspension was added to the sample dispersion unit containing stirrer and stirred at high speed to reduce the particle aggregation then it was measured by photon correlation spectroscopy. ${ }^{7,8}$ For zeta potential analysis, $\mathrm{PH}$ transferosomal vesicles $(100 \mu \mathrm{L})$ were diluted 10 times with distilled water and measured by Malvern analyzer. ${ }^{9}$

\section{Morphology and structure of transferosomes}

The morphology and structure of the drug-loaded transferosomal vesicles were determined with the aid of transmission electron microscopy. Freshly prepared transferosomal dispersions were diluted 10 times with distilled water. A drop of the diluted suspension was then loaded on a carbon-coated copper grid. The excess suspension was adsorbed immediately using filter paper. A drop of aqueous solution of uranyl acetate-positive stain $(10 \% \mathrm{w} / \mathrm{w})$ was directly applied on the deposit for 45 seconds for contrast enhancement. The vesicles were air-dried on the copper grid. After drying, the grid was directly examined using transmission electron microscopy model JEM-1400 microscope; JEOL, Tokyo, Japan. ${ }^{10}$

\section{In vitro drug release from transferosomes}

The release profile of the drug entrapped within transferosomal vesicles was studied using a locally fabricated diffusion cell. Cellophane dialysis tubing (SERVAPOR ${ }^{\circledR}$, pore size $2.5 \mathrm{~nm}$ ) was purchased from SERVA Electrophoresis GmbH, Heidelberg, Germany, with molecular weight cut-off 12,000-14,000. The membrane was hydrated with the receptor medium of PBS ( $\mathrm{pH} 5.5)$ overnight before being mounted between the donor and receptor compartments. The donor medium received the freshly prepared transferosomal suspension sample $(2 \mathrm{~mL})$. The receiving compartment was filled with PBS (30 mL, pH 5.5) and was stirred constantly by a magnetic stirrer to avoid diffusion layer effects. The temperature was maintained at $37^{\circ} \mathrm{C} \pm 0.5^{\circ} \mathrm{C}$ resulting in a membrane surface temperature of $32^{\circ} \mathrm{C}$ to simulate human skin temperature. The freshly prepared transferosomal dispersion was placed evenly in the donor compartment within the double layer of the dialysis tubing. The two ends of the dialysis sac were tightly bound with threads. The sac was hung inside the donor compartment so that the portion of the dialysis sac with the formulation dipped into the receiving medium. Two-milliliter aliquots were withdrawn at predetermined time intervals over 6 hours and immediately replenished with an equal volume of fresh buffer. The sink condition was fulfilled. Triplicate experiments were conducted for each study. All the samples were analyzed for drug content spectrophotometrically at $\lambda=254 \mathrm{~nm}$. The amount of drug released after each time interval was calculated indirectly from the amount of drug entrapped at zero times as the initial amount where $100 \%$ of the drug entrapped and $0 \%$ of the drug released. ${ }^{9,11}$

\section{Preparation and characterization of hydrogel}

Formula number T3 was selected to be incorporated into hydrogel dosage form based on the results of EE, size distribution, and release characteristics. The T3 was embedded in HPMC $(2 \% \mathrm{w} / \mathrm{v})$ hydrogel base. Weighed amounts of the HPMC powder were sprinkled gently on a vortex in beaker $(100 \mathrm{~mL})$ containing $20 \mathrm{~mL}$ of distilled water in which methyl and propyl paraben sodium $(0.1 \% \mathrm{w} / \mathrm{v})$ were dissolved and magnetically stirred at high speed. Freshly prepared transferosomes of T3 were added during the stirring process. Stirring was continued until a smooth homogeneous dispersion was obtained. It was necessary to leave samples 
overnight in the refrigerator to allow complete gel swelling. A similar gel formulation containing an equivalent amount of FPH solution was prepared using the previous procedure. Plain gel free of the drug was formulated under the same conditions. ${ }^{12}$ The final gel products were formulated under aseptic conditions using a BZ Series, model BZ-3SSRX laminar air flow hood. The prepared hydrogels were evaluated for some pharmaceutical properties including percent drug content, uniformity, $\mathrm{pH}$, viscosities, drug release, and some organoleptic characteristics such as color, texture, and transparency. ${ }^{5}$ For determination of percent drug content, gel sample ( $1 \mathrm{~g})$ was withdrawn, weighed into a $100 \mathrm{~mL}$ volumetric flask, and dissolved in PBS ( $\mathrm{pH} 5.5$ ), and then diluted appropriately. The drug content was determined spectrophotometrically at $\lambda=254 \mathrm{~nm} .{ }^{5}$ Similarly, the content uniformity was determined by analyzing drug concentration in different gel samples taken from three to four different places from the container. In case of transferosomal papaverine hydrochloride (TPH) gel, it was shaken with sufficient quantity of Triton X-100 to release the drug and then analyzed spectrophotometrically at $\lambda=254 \mathrm{~nm} .^{8}$ Viscosity determinations of the prepared gel formulations were carried out using a Brookfield DV-II programmable viscometer (spindle 52), which was manufactured by Brookfield Engineering Laboratories, Inc. (USA). The flow behavior was studied by measuring the viscosity at different rates of shear. Rheology studies were conducted in the shear rate range of $1-400$ second $^{-1} .^{5}$ The in vitro drug permeation of FPH and the entrapped TPH from gel formulations were studied using cellophane dialysis tubing with molecular weight cut-off 12,000-14,000, which was previously kept overnight in PBS (pH 5.5). The cellophane membrane was mounted on a diffusion cell assembly with an effective diffusion area of $2.303 \mathrm{~cm}^{2}$. The receptor compartment was filled with PBS (30 mL, pH 5.5) as the receptor medium which was stirred at constant rate of $100 \mathrm{rpm}$ and was maintained at $37^{\circ} \mathrm{C} \pm 0.5^{\circ} \mathrm{C}$ throughout the experiments. The prepared formulation ( $2 \mathrm{~g}$ ) was injected into the dialysis bag in the donor compartment. The diffusion cell was immersed to a depth of $1 \mathrm{~cm}$ below the surface of PBS in the receptor compartment. Sink conditions were fulfilled. An aliquot ( $2 \mathrm{~mL}$ ) was taken from the receptor medium at regular time intervals and was replaced immediately with an equal volume of fresh PBS. Withdrawn aliquots were analyzed spectrophotometrically at $\lambda=254 \mathrm{~nm}$. The cumulative amount of the drug permeated across the cellophane membrane was calculated and plotted against time. The experiments were conducted independently in triplicate. ${ }^{4}$

\section{Stability study}

Stability study of the drug-loaded transferosomes

Physical stability studies of the prepared vesicles were carried out to evaluate the aggregation of vesicles and leakage of drug from them during storage. The prepared transferosomal vesicles were stored in transparent vials covered with plastic cap $\left(10 \mathrm{~mL}\right.$ capacity) at $4^{\circ} \mathrm{C} \pm 1^{\circ} \mathrm{C}, 25^{\circ} \mathrm{C} \pm 1^{\circ} \mathrm{C}$ (room temperature), and $37^{\circ} \mathrm{C} \pm 1^{\circ} \mathrm{C}$ (physiologic temperature) for 3 months. The physical stability of the prepared vesicles was evaluated by particle size and EE measurement over the period of the study. Samples from each transferosomal formulation $(2 \mathrm{~mL})$ were withdrawn periodically. The particle size and encapsulation efficiency of the vesicles were measured as described previously. The physical appearance of vesicles was examined by visual observation for sedimentation. ${ }^{13}$

\section{Stability study of the final gel formulations}

Both the TPH and FPH hydrogels were kept in amber-colored bottles with cap covered by aluminum foil. They were stored at $2^{\circ} \mathrm{C}-8^{\circ} \mathrm{C}$, room temperature, and at $40^{\circ} \mathrm{C} \pm 2{ }^{\circ} \mathrm{C} / 75 \%$ relative humidity $(\mathrm{RH}) \pm 5 \%$ for a period of up to 30 days. Gel samples ( $1 \mathrm{~g}$ ) were taken periodically and analyzed for drug content. The formulations were evaluated after the end of the study interval for change in appearance. ${ }^{14}$

\section{Clinical evaluation of $\mathrm{PH}$ for treatment of ED}

The study was carried out in the outpatient clinic of Dermatology and Andrology Department at Minia University Hospital (Egypt). This study was performed as a Phase I, placebo-controlled investigation of the effects of a topical $\mathrm{PH}$ gel for management of ED. ${ }^{2}$

\section{Subjects}

Nine men between 32 years and 60 years of age (mean age $46.2 \pm 9.32$ years) who presented to the outpatient clinic at Minia University Hospital (Egypt) with a history of ED irrespective of etiology, marital status, and duration of ED were enrolled for the study. Patients were excluded from the study if hormonal or yohimbine therapy has been used within 6 months. All patients had at least a 1 month history of ED. All patients underwent a detailed physical examination followed by focused vascular and neurological examinations. Biochemical investigations (lipid profile, serum testosterone, prolactin, follicle-stimulating hormone, and luteinizing hormone) were carried out when indicated. Potency was defined as the ability to achieve penetration on greater than $75 \%$ of the attempts with a willing partner. ${ }^{2,15}$ All patients who were 
enrolled in the study had organic impotence. The candidates for this case study were classified into three subgroups. The first group consisted of three patients who have a normal blood pressure and not suffering from any other medical troubles. This was named the normal patient group. The second group consisted of three patients who have hypertension and were on medication. This was named the hypertensive patient group. The third group consisted of three subjects who have diabetes and were on medication. This was named the diabetic patient group. This classification is made to show the effect of $\mathrm{PH}$ on the management of ED in various contributing medical conditions of subjects.

The study was carried out according to the guidelines of the Human Subject Ethics Committee, Faculty of Medicine, Minia University Hospital, Minia University, Minia, Egypt. Informed consent has been obtained from all the participants before starting the study. The goal of the study was explained in a brief simple manner and the expected side effects produced from the study were enumerated and well defined. All the subjects were aware of the steps of the study and signed their approval to be enrolled in the study.

\section{Medications}

$\mathrm{PH}$ in both its transferosomal and free form was mixed with HPMC $(2 \% \mathrm{w} / \mathrm{v})$. The prepared hydrogel $(60 \mathrm{mg} / \mathrm{g})$ was used throughout the study. The gel also contained methylparaben sodium salt $(0.1 \% \mathrm{w} / \mathrm{v})$ and propylparaben sodium salt $(0.1 \%$ $\mathrm{w} / \mathrm{v}$ ) as preservative substances. The placebo consisted of the plain HPMC ( $2 \% \mathrm{w} / \mathrm{v})$ hydrogel base without drug.

\section{Study design}

Each patient was evaluated on four separate sessions for an 11-day period. The first session in day 1 was when the topical formulation of TPH gel was applied. The topical formulation of FPH gel was applied in the second session at fourth day. Vital signs like blood pressure and heart rate (pulse) were recorded before the application of the $\mathrm{PH}$ gel. Color flow Doppler ultrasound model, LOGIQ P5 supplied with $11 \mathrm{~L}$ multifrequency (8-13) linear array transducer manufactured by GE Healthcare, Little Chalfont, UK, was used to measure the peak systolic flow velocity and cavernous artery diameter before the application of the PH gel. All examinations were carried out by the same physician's team. With the patient in the supine position, the transducer was placed over the dorsum of the penis with initial scanning performed in the longitudinal and transverse planes. All velocity measurements were obtained at the proximal penile shaft near the base. Doppler angle ranged from 45 degrees to 65 degrees. Cavernous artery diameter and peak systolic flow velocity were measured. The outer dimensions of the arterial wall were used for measurements. About 1-2 g of PH gel was applied by a trained nurse to the penis, scrotum, and perineum. The penis was then covered with plastic wrap for protection. The patient was left for about 1 hour then the vital signs (blood pressure and heart rate) were similarly recorded. The plastic wrap was removed then color flow Doppler ultrasound was used to measure the peak systolic flow velocity and cavernous artery diameter. Patients were reviewed 2 hours after medication for evidence of any unwanted effects. The penis was evaluated for signs of skin irritation. On session three at the eighth day, a placebo consisting of the gel without $\mathrm{PH}$ was applied to the penis, scrotum, and perineum. This administration was performed in a nonblinded fashion in this preliminary trial, because the levels of statistical significance would have required much larger numbers of subjects and this was not the purpose of a Phase I trial. Clinical assessment was for erectile response and vital signs. Color flow Doppler ultrasound was not performed with the placebo gel. Clinical erections were scored as 1 , no effect; 2 , tumescence without rigidity; 3 , tumescence with 70 degree or less of erection; 4, tumescence with 70-90 degrees of erection; and 5, tumescence with more than 90 degrees of erection. On session four at the 11th day, the penis and scrotum were assessed for any skin changes. ${ }^{2}$

\section{Statistical analysis}

All measurements in the study were carried out in triplicate and the reported data were expressed as the mean values \pm standard deviation. One-way analysis of variance followed by the TukeyKramer multiple comparisons test using GraphPad Instat software v.2.05 was used to determine the statistical significance of the differences in encapsulation efficiency and the release data. All $P$-values were two-tailed, and differences were considered significant when the $P$-value was less than $0.05 .{ }^{16}$ Statistical analysis of the data obtained from the case study (cavernous artery diameter, peak systolic flow velocity, blood pressure and heart rate) was performed with computer software. ${ }^{2}$

\section{Results Characterization of the nano- transferosomes}

Table 2 shows the main characteristics of the prepared formulations which encapsulate $\mathrm{PH}$. The EE\% of deformable vesicles was found to be in the range of $18.29 \% \pm 3.06 \%$ to $71.86 \% \pm 1.61 \%$. The formula T3 showed significantly high EE approaching $72 \%(P<0.05)$. All formulations were found to be in the submicron to nano size range. The formula T2 
Table 2 Characteristic parameters of the loaded transferosomal vesicles

\begin{tabular}{llll}
\hline Formula number & Entrapment efficiency $(\%)$ & Mean particle size $(\mathbf{n m})$ & Mean zeta potential $(\mathbf{m V})$ \\
\hline TI & $58.16 \% \pm 1.70 \%$ & 255 & $-50.8 \pm 4.16$ \\
T2 & $27.60 \% \pm 2.40 \%$ & 68.06 & $-66.4 \pm 5.82$ \\
T3 & $71.86 \% \pm 1.61 \%$ & 220.2 & $-33.4 \pm 3.45$ \\
T4 & $46.23 \% \pm 0.75 \%$ & 105.7 & $-71.5 \pm 4.74$ \\
T5 & $34.87 \% \pm 1.74 \%$ & 531.2 & $-80 \pm 6.78$ \\
T6 & $53.19 \% \pm 1.84 \%$ & 396.1 & $-69.2 \pm 5.57$ \\
T7 & $25.68 \% \pm 1.33 \%$ & 440.8 & $-24.7 \pm 4.89$ \\
T8 & $28.60 \% \pm 0.62 \%$ & 447.9 & $-20.5 \pm 5.35$ \\
T9 & $18.29 \% \pm 3.06 \%$ & 144.1 & $-29.2 \pm 4.18$ \\
\hline
\end{tabular}

Note: The values were the means \pm standard deviation from three parallel measurements.

Abbreviation: $\mathrm{T}$, transferosome.

had the smallest size of $68 \mathrm{~nm}$ while the formula $\mathrm{T} 5 \mathrm{had}$ the largest size of $531 \mathrm{~nm}$. The zeta potential values ranged from $-80 \mathrm{mV}$ to $-20.5 \mathrm{mV}$. The transmission electron micrographs of freshly prepared transferosomes showed the outline and the core of the well-identified spherical vesicles confirming the vesicular characteristics. The vesicles have large internal aqueous core in which the drug is embedded. The transmission electron micrographs of freshly prepared (T3) vesicles are shown in Figure 1 (A, B).

The release profile of $\mathrm{PH}$ from different transferosomal formulations in PBS $(0.1 \mathrm{M}, \mathrm{pH} 5.5)$ at $37^{\circ} \mathrm{C}$ was illustrated in Figure 2. All the transferosomal vesicles released more than $90 \%$ of their drug content after 6 hours. Statistical evaluation showed that there is no significant difference in the release extent of $\mathrm{PH}$ from all the preparations $(P>0.05)$. It was found that all the transferosomal vesicles released their contents according to a first-order kinetic model $\left(R^{2}>0.97\right)$.

\section{Characterization of $\mathrm{PH}$ hydrogel formulations}

Formula number T3 was selected to be incorporated in HPMC 2\% (w/v) hydrogel due to its high EE (72\%), small particle size $(220 \mathrm{~nm})$, and good release characteristics. All gel formulae were of semisolid consistency as required for skin application. All gels were elegant and having a transparent appearance. The drug content was within the range of $97 \%-102 \%$ in the TPH gel while the content in the FPH
A

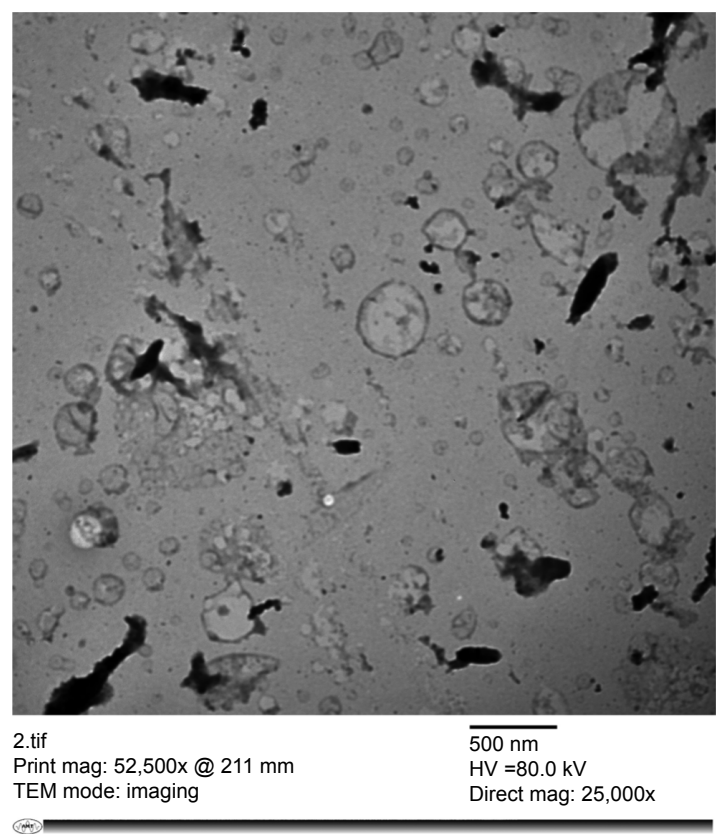

B

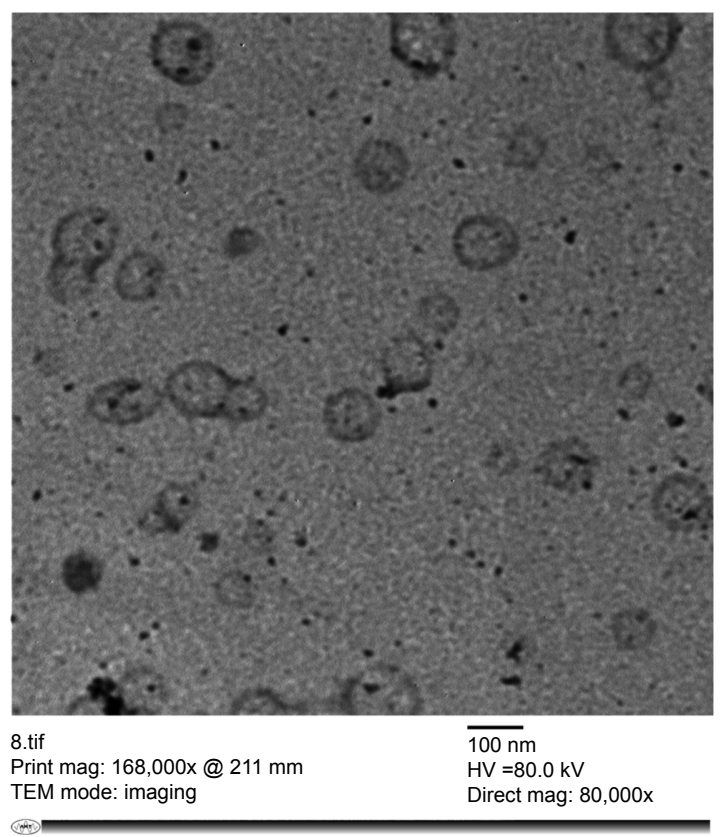

Figure I (A) Transmission electron micrographs of freshly prepared transferosomal vesicles (T3) when stained with uranyl acetate (I0\% w/w) with scale $500 \mathrm{~nm}$. (B) Transmission electron micrographs of freshly prepared transferosomal vesicles (T3) when stained with uranyl acetate (I0\% w/w) with scale I00 $\mathrm{nm}$ (close up). Abbreviations: mag, magnification; T3, transferosome 3; TEM, transmission electron microscopy. 


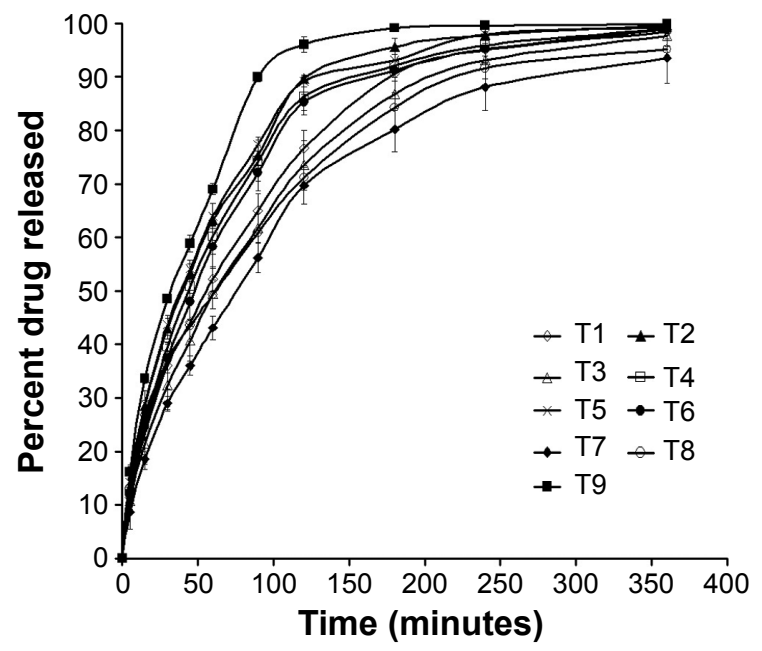

Figure 2 Release profile of all the prepared transferosomes (each value was an average of three measurements \pm standard deviation).

Abbreviation: $\mathrm{T}$, transferosome.

gel was within the range of $98 \%-102 \%$ with no significant difference $(P>0.05$, paired two-tailed $t$-test). These results indicate the high uniformity of the prepared gel formulations. Rheograms of the gel formulations are shown in Figure 3. All the prepared gel samples exhibited pseudoplastic flow with a thixotropic behavior, which was a desirable character in pharmaceutical gels. From the data obtained, it would be observed that for each formula the $\eta_{\max }$ (viscosity of gel at maximum rate of shear) was less than $\eta_{\min }$ (viscosity of gel at minimum rate of shear). Figure 4 shows the percentage $\mathrm{PH}$ released from both the TPH and FPH gel at $37^{\circ} \mathrm{C}$. Statistical analysis of release data showed that there was a significant difference $(P<0.05$, paired two-tailed $t$-test $)$ in release rate of $\mathrm{PH}$ from both the free and the transferosomal gel formula. The release rate from TPH gel appears to be slower than that from the FPH gel. Mechanism of release of

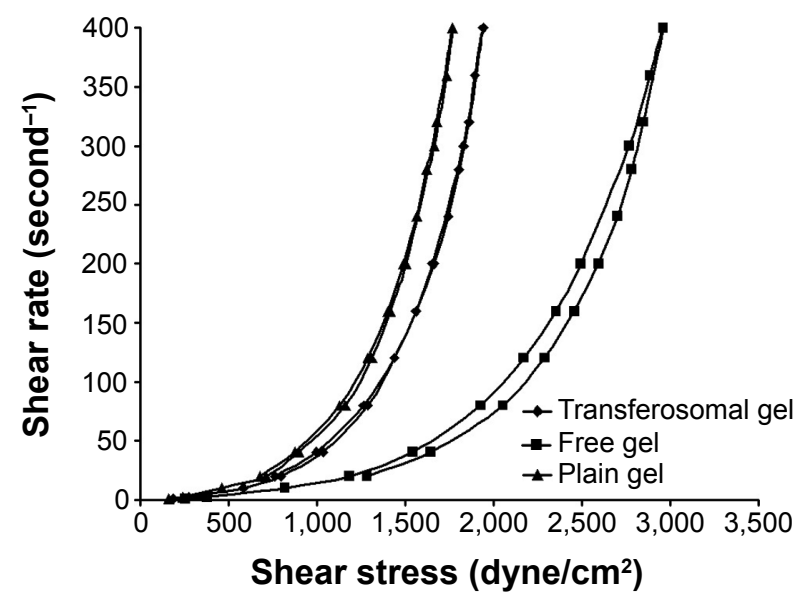

Figure 3 Rheogram representing the flow characteristics of transferosomal, free, and plain gel.

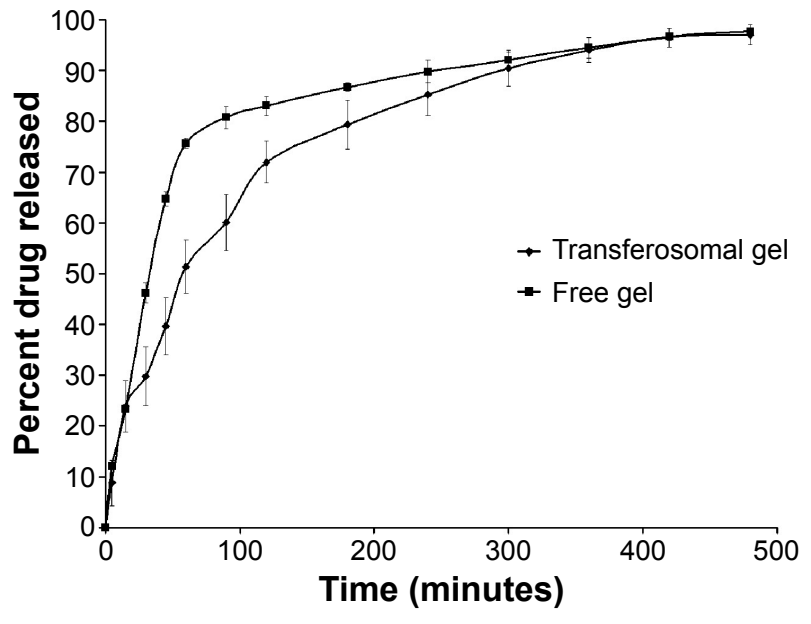

Figure 4 In vitro release profile of papaverine hydrochloride from both the free (nontransferosomal) papaverine hydrochloride solution and that containing papaverine hydrochloride-loaded T3 vesicles incorporated in hydroxypropyl methylcellulose hydrogel $2 \%(\mathrm{w} / \mathrm{v})$ at incubation temperature $\left(37^{\circ} \mathrm{C}\right)$.

Abbreviation: $\mathrm{T}$, transferosome.

PH from the prepared gel formulations was studied and the results showed that both the formulations exhibited a linear release fitting first-order model.

\section{Stability study}

The measurements obtained from different transferosomal formulations during stability study are shown in Tables 3 and 4 . There were no significant changes $(P>0.05)$ in the $\mathrm{EE}$ and vesicle size of the transferosomes stored at $4^{\circ} \mathrm{C}$ in refrigeration conditions. On the other hand, transferosomes stored at higher temperature conditions showed significant changes $(P<0.05)$ in the measuring parameters. A dramatic increase in the vesicle size and drug leakage was observed at both room and physiologic temperature. Vesicles kept at refrigeration condition were able to retain higher percentage of drug compared to others stored at elevated temperatures. By the end of the study, all vesicles stored at $4{ }^{\circ} \mathrm{C}$ were physically stable. No sedimentation or change in color was observed. The transferosomes stored at room temperature showed slight sedimentation, which can be redispersed easily on shaking. At $37^{\circ} \mathrm{C}$, the color of the transferosomal suspensions was changed to pale yellow with the formation of sediment, which was not dispersible upon shaking. The stability study of the prepared hydrogels revealed that there is no significant decrease $(P>0.05)$ in drug content over a period of 30 days for formulations kept at $2^{\circ} \mathrm{C}-8^{\circ} \mathrm{C}$ and $25^{\circ} \mathrm{C}$. A significant reduction $(P<0.05)$ was observed with formulations stored at $40^{\circ} \mathrm{C} \pm 2^{\circ} \mathrm{C} / 75 \% \pm 5 \% \mathrm{RH}$ (Table 5). FPH gel showed decrease in drug content with a lower rate compared to TPH gel. Hydrogels kept at $40^{\circ} \mathrm{C}$ were less transparent than others stored at lower temperatures. 
Table 3 The entrapment efficiency measurements (\%) of the prepared transferosomal vesicles during storage at $4{ }^{\circ} \mathrm{C}, 25^{\circ} \mathrm{C}$, and $37^{\circ} \mathrm{C}$ over a period of 3 months

\begin{tabular}{lllll}
\hline Formula number & Initial measurement & $\mathbf{4}^{\circ} \mathbf{C}$ & $\mathbf{2 5}^{\circ} \mathbf{C}$ & $31.93 \pm 1.63$ \\
\hline TI & $58.16 \pm 1.70$ & $55.32 \pm 1.31$ & $21.82 \pm 0.47$ & $34.19 \pm 1.81$ \\
T2 & $27.60 \pm 2.40$ & $25.92 \pm 1.71$ & $61.92 \pm 1.60$ & $11.01 \pm 1.42$ \\
T3 & $71.86 \pm 1.61$ & $68.90 \pm 0.94$ & $37.84 \pm 0.69$ & $38.05 \pm 1.66$ \\
T4 & $46.23 \pm 0.75$ & $43.42 \pm 2.21$ & $26.93 \pm 0.93$ & $19.18 \pm 0.87$ \\
T5 & $34.87 \pm 1.74$ & $32.36 \pm 1.29$ & $45.48 \pm 1.30$ & $13.59 \pm 1.76$ \\
T6 & $53.19 \pm 1.84$ & $50.12 \pm 0.94$ & $19.07 \pm 1.34$ & $29.04 \pm 1.33$ \\
T7 & $25.68 \pm 1.33$ & $23.25 \pm 1.01$ & $20.30 \pm 1.57$ & $8.63 \pm 2.17$ \\
T8 & $28.60 \pm 0.62$ & $26.21 \pm 1.80$ & $7.82 \pm 1.85$ & $12.36 \pm 1.24$ \\
T9 & $18.29 \pm 3.06$ & $13.88 \pm 0.99$ & & $2.88 \pm 0.92$ \\
\hline
\end{tabular}

Note: The values were the means \pm standard devotion from three parallel measurements.

Abbreviation: $T$, transferosome.

\section{Clinical evaluation of $\mathrm{PH}$ for treatment of ED}

\section{Color flow Doppler measurements}

Tables 6 and 7 show the mean measurements of cavernous diameter and peak systolic flow velocity, respectively, before and after application of both TPH and FPH gel using color flow Doppler ultrasound. Application of the TPH gel resulted in a $47 \%$ statistically significant increase in the cavernous artery diameter for the normal group $(P<0.05$, paired two-tailed $t$-test). An increase in diameter of greater than $65 \%$ was observed in three of nine patients with a TPH gel versus one patient, who received FPH gel. Figure 5A-D were Doppler ultrasound images of the cavernous artery of a normal patient showing a significant increase in the cavernous diameter after application of the TPH gel. The application of the TPH gel resulted in a 105\% statistically significant increase in the peak systolic flow velocity for the normal group ( $P<0.05$, paired two-tailed $t$-test). This value seems to be very positive with regard to the patients with FPH gel who achieved a $46 \%(P<0.05$, paired two-tailed $t$-test) increase in velocity. Two of nine patients with TPH gel had an increase in peak systolic flow velocity of greater than $100 \%$ while patients who received FPH gel had an increase in velocity not exceeding $50 \%$ except one patient who had about $75 \%$ increase in peak systolic flow velocity. Figure $6 \mathrm{~A}-\mathrm{C}$ are Doppler ultrasound images of the cavernous artery of a normal patient showing a significant increase in the peak systolic flow velocity after application of the TPH gel. The application of the PH gel resulted in a statistically nonsignificant increase ( $P>0.05$, paired two-tailed $t$-test) in the color flow Doppler measurements of both the hypertensive and diabetic groups; however, the effect of transferosomal gel was still stronger than that of conventional gel.

\section{Vital signs measurements}

Tables 8 and 9 show the mean measurements of systolic and diastolic blood pressures, respectively, before and after application of both TPH and FPH gel. Significant decrease in systolic and diastolic blood pressure was observed in the hypertensive group after application of the PH gel. Application of a placebo gel showed no significant changes in both systolic and diastolic blood pressures (Table 10). Table 11 shows the mean measurements of pulse before and after application of both TPH and FPH gel. No significant changes were

Table 4 The mean particle size measurements $(\mathrm{nm})$ of the prepared transferosomal vesicles during storage at $4^{\circ} \mathrm{C}, 25^{\circ} \mathrm{C}$, and $37^{\circ} \mathrm{C}$ over a period of 3 months

\begin{tabular}{lllll}
\hline Formula number & Initial measurement & $\mathbf{4}^{\circ} \mathbf{C}$ & $\mathbf{2 5}^{\circ} \mathbf{C}$ & 432.2 \\
\hline T1 & 255 & 288.8 & 270.6 & 805.1 \\
T2 & 68.06 & 76.7 & 489.7 & 517.6 \\
T3 & 220.2 & 242.3 & 347.3 & 993.3 \\
T4 & 105.7 & 121.7 & 818.3 & 750.6 \\
T5 & 531.2 & 567.4 & 585 & $1,580.7$ \\
T6 & 396.1 & 422.6 & 561.6 & $1,232.9$ \\
T7 & 440.8 & 455.3 & 604.6 & $1,016.2$ \\
T8 & 447.9 & 469.7 & 394.5 & $1,125.4$ \\
T9 & 144.1 & 148.2 & & 775.3 \\
\hline
\end{tabular}

Note: The values were the means from three parallel measurements.

Abbreviation: T, transferosome. 
Table 5 The percent drug content (\%) of the prepared hydrogels during storage at $2^{\circ} \mathrm{C}-8^{\circ} \mathrm{C}, 25^{\circ} \mathrm{C}$, and $40^{\circ} \mathrm{C} \pm 2^{\circ} \mathrm{C} / 75 \% \pm 5 \% \mathrm{RH}$ over a period of I month

\begin{tabular}{lllll}
\hline Formulation & Days & \multicolumn{2}{l}{ Drug content (\%) } & \\
\cline { 2 - 4 } & & $\mathbf{2}^{\circ} \mathbf{C}-\mathbf{8}^{\circ} \mathbf{C}$ & $\mathbf{2 5}{ }^{\circ} \mathbf{C}$ & $\mathbf{4 0} \mathbf{C}^{\circ} \pm \mathbf{2}^{\circ} \mathbf{C} / \mathbf{7 5} \% \pm \mathbf{5} \% \mathbf{R H}$ \\
\hline TPH gel & 0 & $99.72 \pm 2.61$ & $99.72 \pm 2.61$ & $99.72 \pm 2.61$ \\
& 5 & $99.61 \pm 2.35$ & $98.55 \pm 1.51$ & $95.92 \pm 1.16$ \\
& 10 & $99.34 \pm 1.94$ & $97.68 \pm 1.01$ & $92.16 \pm 2.18$ \\
& 15 & $98.95 \pm 1.99$ & $96.81 \pm 0.71$ & $87.98 \pm 1.22$ \\
FPH gel & 30 & $98.05 \pm 2.11$ & $95.28 \pm 1.39$ & $80.81 \pm 0.59$ \\
& 0 & $99.79 \pm 2.18$ & $99.79 \pm 2.18$ & $99.79 \pm 2.18$ \\
& 5 & $99.74 \pm 1.50$ & $99.43 \pm 2.60$ & $98.04 \pm 1.82$ \\
& 10 & $99.69 \pm 2.59$ & $98.74 \pm 1.59$ & $96.19 \pm 0.55$ \\
& 15 & $99.58 \pm 0.68$ & $98.19 \pm 1.74$ & $92.77 \pm 1.56$ \\
\end{tabular}

Note: The values were the means \pm standard deviation from three parallel measurements.

Abbreviations: TPH, transferosomal papaverine hydrochloride; $\mathrm{FPH}$, free papaverine hydrochloride; $\mathrm{RH}$, relative humidity.

observed in heart rate after application of $\mathrm{PH}$ gel; however, a $12.14 \%$ statistically significant decrease in pulse $(P<0.05$, paired two-tailed $t$-test) was observed in the normal group after the application of a placebo gel (Table 12).

\section{Side effects}

No undesirable side effects were observed. Monitoring of patients after application of the transferosomal gel for evidence of any adverse effects like skin irritation, erythematous rash, facial flushing, dizziness, or pain at the site of gel application ensures the safety of the formula.

\section{Clinical erections}

Three of nine patients (33\%) had grade 3 erections while one patient $(11 \%)$ had grade 4 erections. These positive responses were observed after the application of TPH gel. The patients with a positive response had no clinical erections with a placebo gel. A total of five patients $(56 \%)$ had no response.

\section{Discussion}

Transferosomes are elastic, flexible, and ultradeformable liposomal vesicles, which have better penetration ability than conventional liposomes. As a result, they were used for noninvasive delivery of drugs into or across the skin. Therefore, in the present study, deformable lipid vesicles "transferosomes" were formulated. ${ }^{17}$ The vesicles were prepared using different types and concentrations of surfactants (edge activators). The concentration of lecithin and cholesterol was kept as constant for all the formulations. Edge activators are single-chain components, which when incorporated in the vesicular formulations destabilize the vesicles and enhance the deformability of the phospholipid bilayer by decreasing the interfacial tension. ${ }^{9}$ On the other hand, EE\% is an important parameter in case of transferosomal formulations as it may affect the drug release and skin deposition. The formula T3 showed significantly high EE\% approaching $72 \%(P<0.05)$. The high EE\% of T3 may be attributed to the presence of SDC that enhances the vesicle elasticity and flexibility rendering the transferosomal membrane able to encapsulate large amounts of the drug. ${ }^{5}$ High concentration of cholesterol has a stabilizing effect on vesicular membrane. Cholesterol decreases the fluidity of the bilayers by filling empty spaces among the phospholipid molecules anchoring them more strongly into the structure;

Table 6 Mean color flow Doppler measurements (cavernous artery diameter) before and after the application of both transferosomal and free papaverine hydrochloride gel

\begin{tabular}{|c|c|c|c|c|c|c|c|c|}
\hline \multirow[t]{3}{*}{ Patient groups } & \multicolumn{8}{|c|}{ Cavernous artery diameter $(\mathrm{mm})$} \\
\hline & \multicolumn{4}{|l|}{ TPH gel } & \multicolumn{4}{|l|}{ FPH gel } \\
\hline & $\begin{array}{l}\text { Before } \\
\text { application }\end{array}$ & $\begin{array}{l}\text { After } \\
\text { application }\end{array}$ & $\begin{array}{l}\text { Percent } \\
\text { increase (\%) }\end{array}$ & $P$-value & $\begin{array}{l}\text { Before } \\
\text { application }\end{array}$ & $\begin{array}{l}\text { After } \\
\text { application }\end{array}$ & $\begin{array}{l}\text { Percent } \\
\text { increase (\%) }\end{array}$ & $P$-value \\
\hline Normal patient & $0.53 \pm 0.076$ & $0.78 \pm 0.23$ & 47 & Significant & $0.65 \pm 0.1$ & $0.95 \pm 0.1$ & 46 & Not significant \\
\hline Hypertensive patient & $0.62 \pm 0.058$ & $0.75 \pm 0.1$ & 22 & Not significant & $0.75 \pm 0.15$ & $0.95 \pm 0.25$ & 27 & Not significant \\
\hline Diabetic patient & $0.7 \pm 0.14$ & $1.025 \pm 0.035$ & 46 & Not significant & $0.7 \pm 0.05$ & $0.8 \pm 0.1$ & 14.5 & Not significant \\
\hline
\end{tabular}

Note: The values were the means \pm standard deviation from three parallel measurements.

Abbreviations: TPH, transferosomal papaverine hydrochloride; FPH, free papaverine hydrochloride. 
Table 7 Mean color flow Doppler measurements (peak systolic flow velocity) before and after application of both transferosomal and free papaverine hydrochloride gel

\begin{tabular}{|c|c|c|c|c|c|c|c|c|}
\hline \multirow[t]{3}{*}{ Patient groups } & \multicolumn{8}{|c|}{ Peak systolic flow velocity $(\mathrm{cm} / \mathrm{s})$} \\
\hline & \multicolumn{4}{|l|}{ TPH gel } & \multicolumn{4}{|l|}{ FPH gel } \\
\hline & $\begin{array}{l}\text { Before } \\
\text { application }\end{array}$ & $\begin{array}{l}\text { After } \\
\text { application }\end{array}$ & $\begin{array}{l}\text { Percent } \\
\text { increase (\%) }\end{array}$ & $P$-value & $\begin{array}{l}\text { Before } \\
\text { application }\end{array}$ & $\begin{array}{l}\text { After } \\
\text { application }\end{array}$ & $\begin{array}{l}\text { Percent } \\
\text { increase (\%) }\end{array}$ & $P$-value \\
\hline Normal patient & $5.95 \pm 1.72$ & $12.2 \pm 5.26$ & 105 & Significant & $13.8 \pm 1.2$ & $20.2 \pm 1.3$ & 46 & Significant \\
\hline Hypertensive patient & $7.27 \pm 2.04$ & $9.48 \pm 4.74$ & 31 & Not significant & $12.15 \pm 1.25$ & $14.7 \pm 0.9$ & 21 & Not significant \\
\hline Diabetic patient & $6.3 \pm 0.21$ & $7.75 \pm 0.28$ & 23 & Not significant & $16.6 \pm 4.8$ & $19.8 \pm 1.15$ & 19 & Not significant \\
\hline
\end{tabular}

Note: The values were the means \pm standard deviation from three parallel measurements.

Abbreviations: TPH, transferosomal papaverine hydrochloride; $\mathrm{FPH}$, free papaverine hydrochloride.

moreover, it reduces the permeability of the membrane to the water-soluble molecules due to the above effect, and therefore, cholesterol was able to prevent the leakage of the drug from the vesicles and increase the EE\% effectively. ${ }^{11,18}$ In the present study, there were significant differences in particle size between transferosomes containing different edge activators. The formula T2 which contains SDC has the smallest size among all preparations, while the formula T5 which contains span 60 has the largest size. This reduction of the particle size diameter of elastic SDC transferosomes may be attributed to the increased flexibility and reduced surface tension of these vesicles. ${ }^{9}$ Moreover, particle size increased
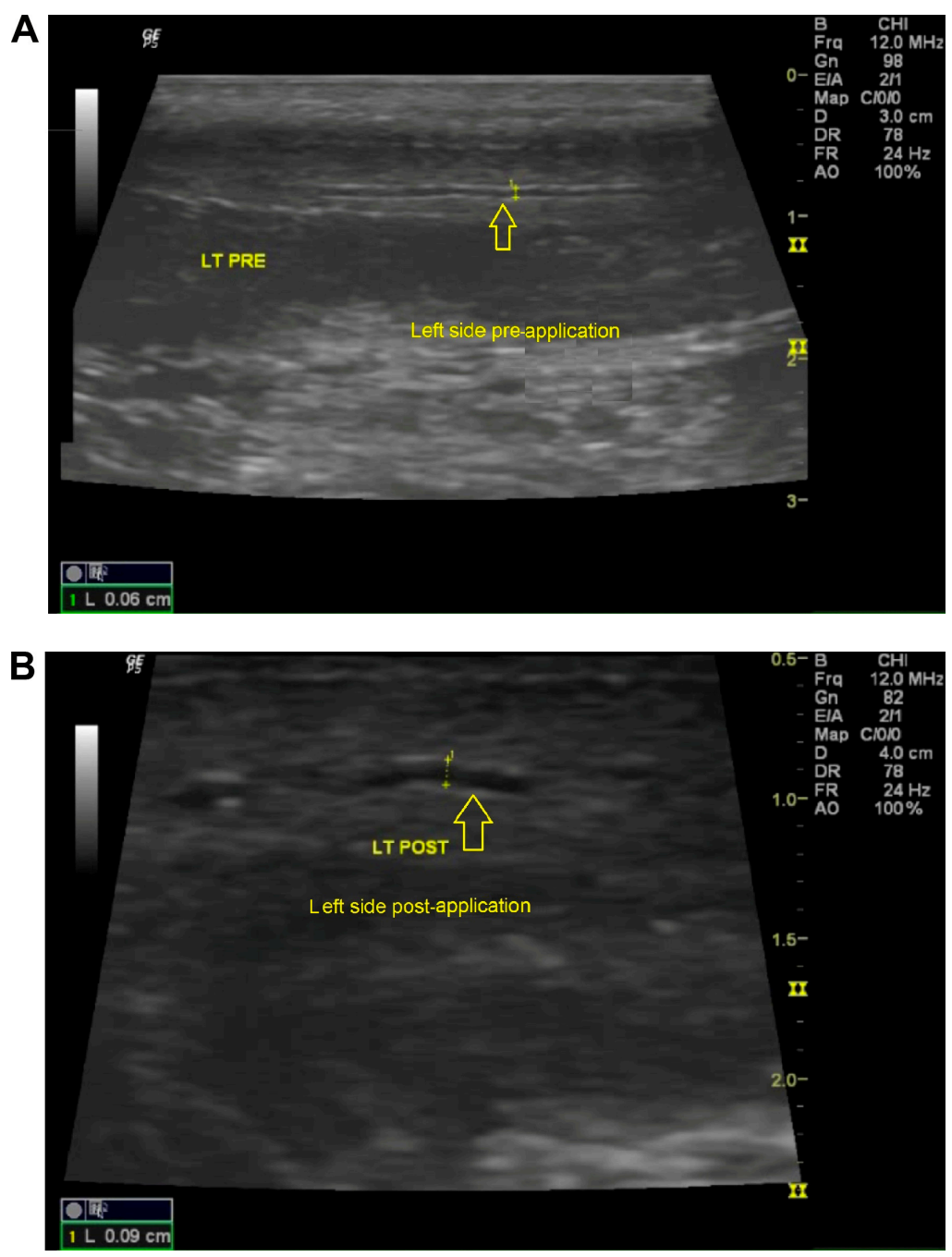

Figure 5 (Continued) 

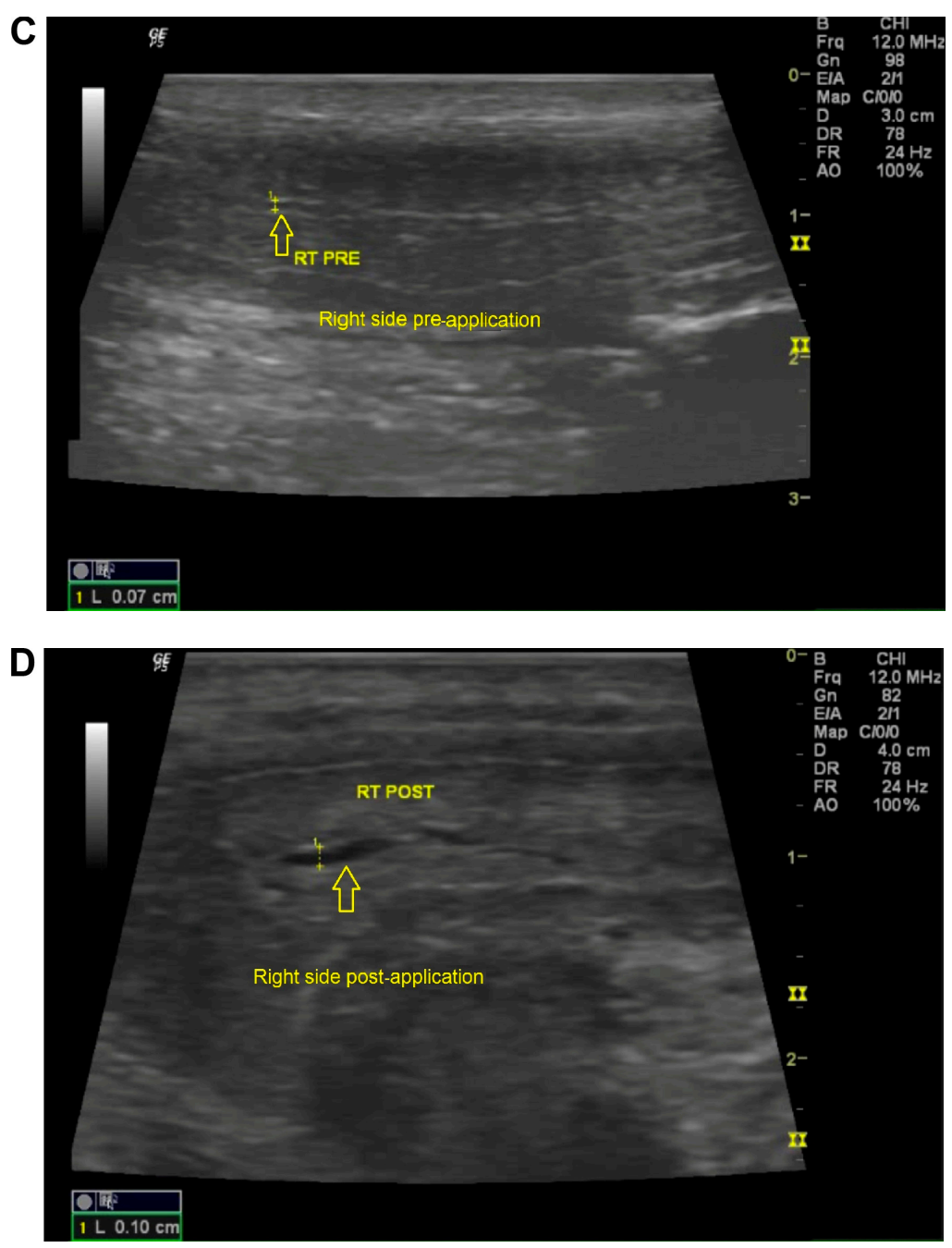

Figure 5 (A) Doppler ultrasound image showing the diameter of the left side of cavernous artery (arrow) of a normal patient before the application of TPH gel. (B) Doppler ultrasound image showing the diameter of the left side of cavernous artery (arrow) of a normal patient I hour after the application of TPH gel. (C) Doppler ultrasound image showing the diameter of the right side of cavernous artery (arrow) of a normal patient before application of TPH gel. (D) Doppler ultrasound image showing the diameter of the right side of cavernous artery (arrow) of a normal patient I hour after the application of TPH gel.

Abbreviations: LT, left side; PRE, pre-application; POST, post-application; RT, right side; TPH, transferosomal papaverine hydrochloride.

along with surfactants possessing lower HLB (hydrophilic lipophilic balance). The trend between HLB and particle size might be attributed to the increase in surface free energy accompanying increasing hydrophobicity of surfactant. Surfactants interacted with lipid head groups in the membrane would increase the packing density of the layer, which might lead to high surface free energy. Thus, the increasing surface free energy led to fusion between lipid bilayers. As a result, vesicles with larger size would be produced. ${ }^{10}$ The zeta potential values showed that the prepared transferosomes have sufficient charge to avoid aggregation of vesicles due to strong electrostatic repulsion between them. These results indicate the good stability of the prepared vesicles. The negatively charged transferosomes strongly improved skin permeation of drugs in transdermal delivery.
The skin surface has slight negative charge. Therefore, the negative charge of the optimized transferosomal gel containing drug might cause little influence in improving drug permeation through skin due to electrostatic repulsion between the charge of the skin surface and the optimized gel. ${ }^{8,19}$ As expected, encapsulation of $\mathrm{PH}$ into transferosomes led to a controlled release rate due to the well-known reservoir effect of transferosomes. ${ }^{19}$ The release profiles of $\mathrm{PH}$ from transferosomal vesicles of different compositions were apparently biphasic release processes, showing a relatively large burst effect over the first 2 hours, followed by a slower release phase over the next 4 hours. Similar results were obtained from the study of flurbiprofen release from different niosomal preparations. This could be attributed to the highly ordered lipid particles, which cannot accommodate large 

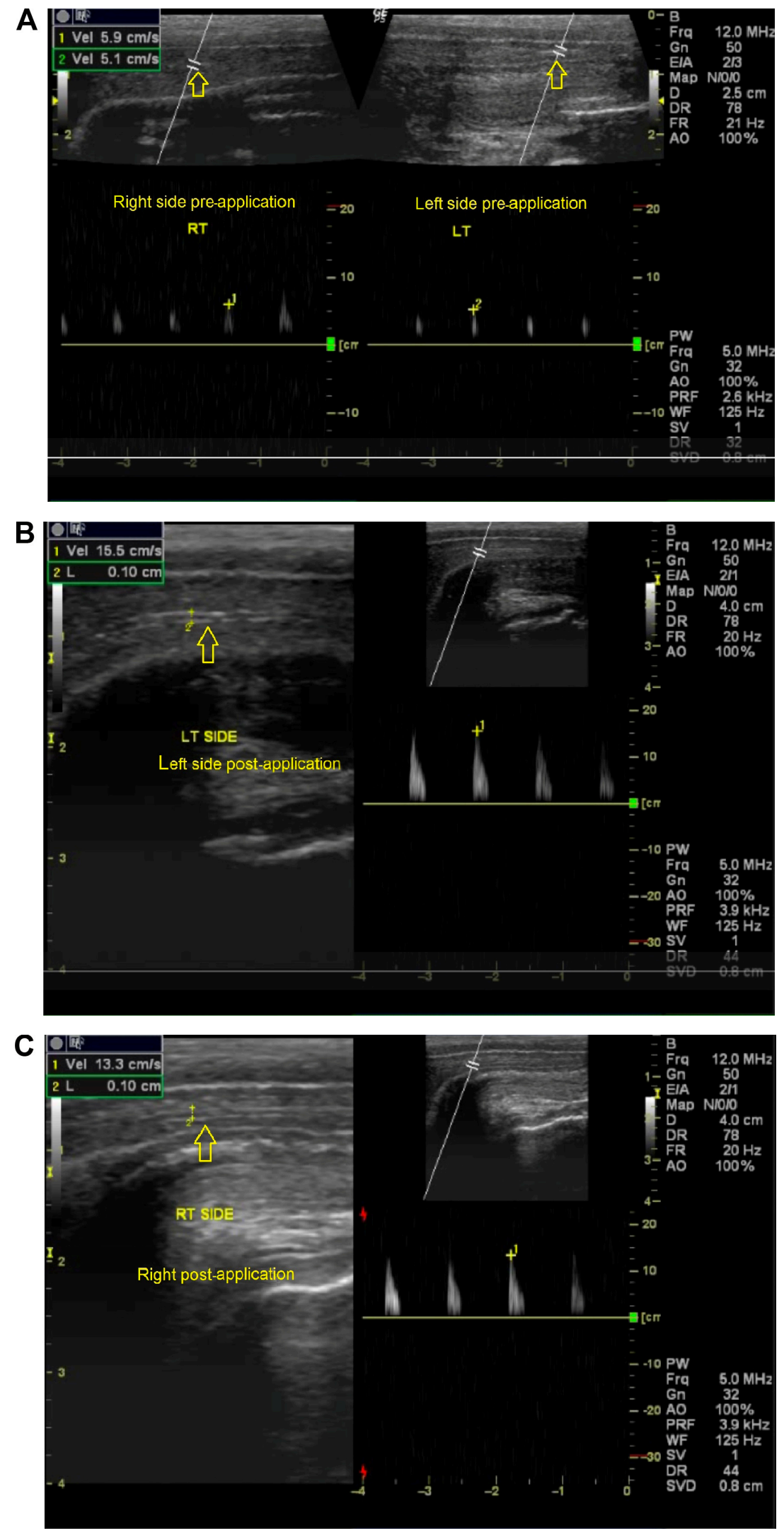

Figure 6 (A) Doppler ultrasound image showing the peak systolic flow velocity of both the left and the right side of cavernous artery of a normal patient before the application of TPH gel. (B) Doppler ultrasound image showing the peak systolic flow velocity of the left side of cavernous artery of a normal patient I hour after the application of TPH gel. (C) Doppler ultrasound image showing the peak systolic flow velocity of the right side of cavernous artery of a normal patient I hour after the application of TPH gel. Notes: In Figure 6A, both arrows point to the left side and the right side of cavernous artery respectively. In Figure 6B, the arrow points to the left side of cavernous artery. In Figure 6C, the arrow points to the right side of cavernous artery.

Abbreviations: LT, left side; RT, right side; TPH, transferosomal papaverine hydrochloride. 
Table 8 Mean vital signs measurements (systolic blood pressure) before and after application of both transferosomal and free papaverine hydrochloride gel

\begin{tabular}{|c|c|c|c|c|c|c|c|c|}
\hline \multirow[t]{3}{*}{ Patient groups } & \multicolumn{8}{|c|}{ Systolic blood pressure $(\mathrm{mmHg})$} \\
\hline & \multicolumn{4}{|l|}{ TPH gel } & \multicolumn{4}{|l|}{ FPH gel } \\
\hline & $\begin{array}{l}\text { Before } \\
\text { application }\end{array}$ & $\begin{array}{l}\text { After } \\
\text { application }\end{array}$ & $\begin{array}{l}\text { Percent } \\
\text { decrease (\%) }\end{array}$ & $P$-value & $\begin{array}{l}\text { Before } \\
\text { application }\end{array}$ & $\begin{array}{l}\text { After } \\
\text { application }\end{array}$ & $\begin{array}{l}\text { Percent } \\
\text { decrease (\%) }\end{array}$ & $P$-value \\
\hline Normal patient & $133 \pm 5.77$ & $107 \pm 20.8$ & 20 & Not significant & $107 \pm 5.77$ & $92 \pm 2.89$ & 14 & Not significant \\
\hline Hypertensive patient & $187 \pm 20.82$ & $147 \pm 20.82$ & 21.5 & Significant & $167 \pm 15.28$ & $140 \pm 10$ & 16 & Significant \\
\hline Diabetic patient & $155 \pm 7.07$ & $140 \pm 14.14$ & 10 & Not significant & $133 \pm 1 \mid .55$ & $120 \pm 10$ & 10 & Not significant \\
\hline
\end{tabular}

Note: The values were the means \pm standard deviation from three parallel measurements.

Abbreviations: TPH, transferosomal papaverine hydrochloride; FPH, free papaverine hydrochloride.

amounts of drug and this is the reason for drug expulsion. ${ }^{20}$ Moreover, this effect may be the result of an inherent property of the bilayer or transferosome structure or reflect the loss of surface-associated material. Some literatures report that the initial fast rate of release was commonly attributed to the drug detachment from transferosomal surface, while the later slow release was attributed to the sustained drug release from the inner lamellae. The burst effect varies with the vesicle type and lipid composition. ${ }^{21,22}$ Release kinetic analysis of all transferosomal formulations was studied for different kinetic equations (zero order, first order, and Higuchi equation). The best fit with a higher correlation coefficient $\left(R^{2}>0.97\right)$ was found with the first-order model for all the transferosomal formulations, suggesting that drug transport out of the transferosomal vesicles was driven mainly according to first-order kinetics. The formula $\mathrm{T} 3$ was selected to be incorporated in the HPMC $2 \%(\mathrm{w} / \mathrm{v})$ hydrogel base. All the prepared gels exhibited pseudoplastic behavior with thixotropic character. This pseudoplasticity results from a colloidal network structure that aligns itself in the direction of shear, thereby decreasing the viscosity as the shear rate increases. ${ }^{4}$ Formulations were subjected to different rates of shear. The plot of rate of shear against shearing stress (Figure 3) shows the thixotropic behavior of gels. As shear was applied, flow starts and structure begins to break down as the points of contact were disrupted and polymeric chain aligned, exhibiting shear thinning. Upon removal of stress, the structure starts to reform and progressive restoration of consistency occurs. The gels had a lower viscosity at any rate of shear on the down curve than it had on the up curve. This might be due to the fact that the network structure between neighboring gel chains as well as the entanglements between long polymer chain segments breaks down. The area of the loop between the up and down flow curves of a rheogram is a measure of the thixotropic breakdown. In all the prepared gel formulations, the area of loop was found with a different extent indicating a thixotropic behavior. ${ }^{23}$ The release of $\mathrm{PH}$ was modified when transferosomes were loaded in the gel systems. The release rate of PH from TPH gel formulations was significantly lower than that from the FPH gel formulations. This may be attributed to the presence of cholesterol, which impacts rigidity in the vesicle membrane. It has been previously proven that in case of hydrophilic drugs, vesicle membrane rigidity is the most important parameter that determines the release rate of the drug from transferosomal gels. ${ }^{5}$ The slow PH release from the TPH hydrogel can be attributed also to the number of barriers to the diffusion pathways of the drug from the hydrogel. The drug first passes through the vesicular membranes, then permeates into the surrounding hydrogel network, and finally to the external medium.

Table 9 Mean vital signs measurements (diastolic blood pressure) before and after application of both transferosomal and free papaverine hydrochloride gel

\begin{tabular}{|c|c|c|c|c|c|c|c|c|}
\hline \multirow[t]{3}{*}{ Patient groups } & \multicolumn{8}{|c|}{ Diastolic blood pressure $(\mathrm{mmHg})$} \\
\hline & \multicolumn{4}{|l|}{ TPH gel } & \multicolumn{4}{|l|}{ FPH gel } \\
\hline & $\begin{array}{l}\text { Before } \\
\text { application }\end{array}$ & $\begin{array}{l}\text { After } \\
\text { application }\end{array}$ & $\begin{array}{l}\text { Percent } \\
\text { decrease (\%) }\end{array}$ & $P$-value & $\begin{array}{l}\text { Before } \\
\text { application }\end{array}$ & $\begin{array}{l}\text { After } \\
\text { application }\end{array}$ & $\begin{array}{l}\text { Percent } \\
\text { decrease (\%) }\end{array}$ & $P$-value \\
\hline Normal patient & $77 \pm 15.28$ & $62 \pm 10.4$ & 19.5 & Not significant & $67 \pm 5.77$ & $60 \pm 5$ & 10 & Not significant \\
\hline Hypertensive patient & $107 \pm 11.55$ & $87 \pm 7.64$ & 19 & Significant & $102 \pm 7.64$ & $93 \pm 5.77$ & 8 & Significant \\
\hline Diabetic patient & $97 \pm 3.54$ & $85 \pm 7.07$ & 13 & Not significant & $88 \pm 7.64$ & $83 \pm 10.41$ & 6 & Not significant \\
\hline
\end{tabular}

Note: The values were the means \pm standard deviation from three parallel measurements.

Abbreviations: TPH, transferosomal papaverine hydrochloride; FPH, free papaverine hydrochloride. 
Table 10 Mean vital signs measurements (blood pressure) before and after application of placebo gel

\begin{tabular}{|c|c|c|c|c|c|c|}
\hline \multirow[t]{2}{*}{ Patient groups } & \multicolumn{3}{|c|}{ Systolic blood pressure (mmHg) } & \multicolumn{3}{|c|}{ Diastolic blood pressure (mmHg) } \\
\hline & Before application & After application & $P$-value & Before application & After application & $P$-value \\
\hline Normal patient & $127 \pm 5.77$ & $132 \pm 2.89$ & Not significant & $82 \pm 12.58$ & $77 \pm 5.77$ & Not significant \\
\hline Hypertensive patient & $178 \pm 12.58$ & $177 \pm 15.28$ & Not significant & $98 \pm 2.89$ & $95 \pm 5$ & Not significant \\
\hline Diabetic patient & $|47 \pm| 5.28$ & $145 \pm 13.23$ & Not significant & $85 \pm 18.03$ & $88 \pm 16.07$ & Not significant \\
\hline
\end{tabular}

Note: The values were the means \pm standard deviation from three parallel measurements.

This takes longer time compared to the FPH that released directly from the gel matrix to the surrounding medium. ${ }^{16}$

The stability of transferosomes is an important factor to be considered in the development of an efficient drug delivery system. In the present study, the stability of different transferosomal vesicles and the final gel formulations was evaluated at different temperatures, to imitate physiological conditions. The results obtained have revealed that the prepared vesicles were physically and chemically stable in terms of aggregation and fusion when they were stored in refrigeration condition. No significant changes in the physical appearance, particle size, and EE were observed for different transferosomal vesicles during the course of stability study at $4^{\circ} \mathrm{C}$. However, the formulations kept at $25^{\circ} \mathrm{C}$ and $37^{\circ} \mathrm{C}$ showed a significant increase in particle size, which may be attributed to the aggregation or swelling of vesicles. A slight decrease in the EE was observed showing a significant leakage of $\mathrm{PH}$ from different formulations over time. Significant drug leakage at elevated temperatures may be attributed to the enhanced fluidity of vesicular membrane. Loss of the drug from the vesicles stored at elevated temperatures may be due to the influence of temperature on the gel to liquid transition of lipid bilayers together with possible chemical degradation of the phospholipids constituting the vesicular membrane, leading to defects in membrane packing. ${ }^{14}$ The physical stability of the FPH gel seems to be better than that of the TPH gel. The decrease in drug content of TPH gel appears to occur with a faster rate compared to FPH gel. This may be attributed to the bad stability of the vesicular system. The results of the present study suggest that storage of the transferosomal product in refrigeration conditions can minimize stability problems of transferosomes. The incorporation of vesicles into gel system could enhance the stability of the formulation. This may be attributed to the high viscosity of the hydrogel base, which retarded the movement and fusion of vesicles. ${ }^{24}$

The National Institutes of Health defined ED, a relatively common problem affecting men of all ages, as "the inability to achieve and/or maintain an erection sufficient for satisfactory sexual activity". ED was found to be an age-dependent disorder with a prevalence ranging from $0.1 \%$ at 20 years of age to $75 \%$ at 80 years. ${ }^{15}$ A study was performed by Kim et $\mathrm{al}^{2}$ to investigate the effects of topical papaverine base and hydrochloride gel on safety, systemic absorption, penile vasodilation, and clinical erection. It was concluded that topical papaverine gel appears to be safe and well tolerated after application to the genitalia and increases blood flow to the penis with a $15 \%$ and $20 \%$ base preparation. ${ }^{2}$ The present study examined the safety and efficacy of $\mathrm{PH}$ for management of ED as a topical agent. This study included the evaluation of the pharmacological effects of TPH gel and comparing the results obtained with that produced from FPH gel. The results revealed that $\mathrm{PH}$ would be more efficient for treatment of ED when it was loaded in transferosomal vesicles than conventional gel. This may be attributed to the unique characteristics of transferosomes as a drug delivery

Table II Mean vital signs measurements (heart rate) before and after application of both transferosomal and free papaverine hydrochloride gel

\begin{tabular}{|c|c|c|c|c|c|c|c|c|}
\hline \multirow[t]{3}{*}{ Patient groups } & \multicolumn{8}{|c|}{ Heart rate (beats/minute) } \\
\hline & \multicolumn{4}{|l|}{ TPH gel } & \multicolumn{4}{|l|}{ FPH gel } \\
\hline & $\begin{array}{l}\text { Before } \\
\text { application }\end{array}$ & $\begin{array}{l}\text { After } \\
\text { application }\end{array}$ & $\begin{array}{l}\text { Percent } \\
\text { decrease (\%) }\end{array}$ & $P$-value & $\begin{array}{l}\text { Before } \\
\text { application }\end{array}$ & $\begin{array}{l}\text { After } \\
\text { application }\end{array}$ & $\begin{array}{l}\text { Percent } \\
\text { decrease (\%) }\end{array}$ & $P$-value \\
\hline Normal patient & $87 \pm 12.86$ & $75 \pm 3.06$ & 13 & Not significant & $75 \pm 3$ & $7 I \pm 6.1 I$ & 5 & Not significant \\
\hline Hypertensive patient & $82 \pm 13.8$ & $69 \pm 15.59$ & 15.5 & Not significant & $89 \pm 3.61$ & $75 \pm 5$ & 16 & Not significant \\
\hline Diabetic patient & $|07 \pm 0.7|$ & $94 \pm 2.12$ & 12 & Not significant & $100 \pm 5$ & $89 \pm 3.61$ & II & Not significant \\
\hline
\end{tabular}

Note: The values were the means \pm standard deviation from three parallel measurements.

Abbreviations: TPH, transferosomal papaverine hydrochloride; FPH, free papaverine hydrochloride. 
Table I 2 Mean vital signs measurements (heart rate) before and after application of placebo gel

\begin{tabular}{|c|c|c|c|c|}
\hline \multirow[t]{2}{*}{ Patient groups } & \multicolumn{4}{|c|}{ Heart rate (beats/minute) } \\
\hline & Before application & After application & Percent decrease (\%) & $P$-value \\
\hline Normal patient & $93 \pm 11.59$ & $82 \pm 9.54$ & 12.14 & Significant \\
\hline Hypertensive patient & $78 \pm 6.51$ & $73 \pm 8.19$ & 6.81 & Not significant \\
\hline Diabetic patient & $96 \pm 6$ & $89 \pm 8.74$ & 6.94 & Not significant \\
\hline
\end{tabular}

Note: The values were the means \pm standard deviation from three parallel measurements.

system. A transferosome is a highly adaptable and stressresponsive ultradeformable vesicle. Interdependency of local composition and shape of the bilayer makes the vesicle both self-regulating and self-optimizing. This enables the transferosomes to cross various transport barriers efficiently and then act as a drug carrier for noninvasive targeted drug delivery and sustained release of therapeutic agents. The transdermal delivery improves the local effects of $\mathrm{PH}$; moreover, it minimizes its systemic absorption. ${ }^{25}$ The observed decline in the effect of PH in diabetic patients may be attributed to the fact that the treatment of diabetes-induced ED was often difficult due to its multifactorial etiology. Consequently, a global approach, requiring not one but several treatment strategies was needed for the management of ED, instead of an approach localized to the organ. ${ }^{26}$ The weak effect of $\mathrm{PH}$ in hypertensive patients was attributed to the fact that the subjects of this group were on antihypertensive medications for two days before the start of study. The pharmacological management of hypertension has long been considered as the main reason of ED; ED was considered the important factor that led to nonadherence to antihypertensive therapy. ${ }^{27}$ Reviewing the list of antihypertensive medications administered by the group subjects has proven that $\beta$-blockers (propranolol) and thiazide diuretics (hydrochlorothiazide) were among the medications taken by the group members. $\beta$-blockers have been considered a major cause of ED, which was associated with increased risk of sexual dysfunction and impotence. Thiazide diuretics have been the most implicated class of antihypertensive medications with respect to erectile function. They exert negative effects on sexual function even when used as adjunct therapy. The current treatment of hypertension for this group subjects was recommended to be substituted with angiotensin receptor blockers (Losartan) or angiotensin converting enzyme inhibitors (Captopril). Both medications exert beneficial effects on sexual function in hypertensive patients. ${ }^{27}$ Significant changes in systolic and diastolic blood pressure were noticed after application of PH gel for hypertensive patients. These changes may be from mild systemic absorption of $\mathrm{PH}$, which causes vasodilation and as a result, a drop in the blood pressure occurs. However, other factors may be involved such as the prolonged recumbent position of the patient or relaxation after onset of the application. ${ }^{2}$ The influence of the TPH gel on the blood pressure appears to goes deeper than that of FPH gel. This may be attributed to the enhanced absorption with transferosomal gel preparation. No significant changes were observed in heart rate after the application of $\mathrm{PH}$ gel; however, a statistically significant decrease in the pulse was found after the application of a placebo gel for normal group. These findings may deny the systemic absorption of $\mathrm{PH}$ after topical application to the genitalia. Topical PH appears to be safe and well tolerated. No undesirable side effects were observed. This confirms the minimal systemic uptake of the drug after topical application and ensures the direct local effects of $\mathrm{PH}$ at the penile level.

The clinical evaluation of the pharmacological effects of vasoactive agents like $\mathrm{PH}$ on ED versus other oral phosphodiesterase inhibitors (PDE5) such as sildenafil was an issue of great interest. Viswaroop et a ${ }^{15}$ evaluated the use of oral sildenafil as a substituent of intracavernosal papaverine. The results obtained have shown that oral sildenafil was as effective as papaverine injection. ${ }^{15}$ Another study performed by Copel et al revealed that the clinical response of patients treated with combined intracavernosal injection of papaverine, prostaglandin E1, and phentolamine was significantly higher compared to oral sildenafil with audiovisual sexual stimulation. ${ }^{28}$ Yang et al indicated that more patients had better responses to intracavernosal injection therapy than oral PDE5 administration. However, both medications showed similar effects on the penile color flow Doppler measurements. ${ }^{29}$

The results of the previously reviewed studies showed that the effect of intracavernosal injections of vasoactive agents seems to have more potential than oral PDE5 medications. The present study revealed that TPH gel is not as effective as intracavernous injection therapy. Overall, the obtained results ensure that the topically applied formulation has some potential but not to the degree of intracavernous injections or other common PDE5 oral medications; however, further development and optimization of the formulation was encouraged in terms of efficacy and toxicity. 


\section{Conclusion}

PH-loaded transferosomal vesicles were successfully prepared, characterized, and evaluated. The formula T3 acquired best characteristics and therefore was selected to be incorporated in a hydrogel dosage form. The results of the present study revealed that the TPH gel can be used to enhance penile skin delivery of drug. The color flow Doppler measurements showed that the TPH gel has better pharmacological effect in the management of ED compared to the FPH gel. This study has shown promising results, and hence, there is feasibility of delivering PH through transferosomal transdermal gel. Thus, the developed TPH formulation may prove to be a promising carrier for PH for the treatment of ED, especially due to their simple production and simplistic scale-up. Further study on larger number of patients to investigate clinical efficacy of the drug when it was formulated in a topical dosage form compared to intracavernous injection therapy could be beneficial in removing any suspicion regarding the efficiency of TPH.

\section{Recommendations}

TPH gel is not as effective as intracavernous injection therapy but may have promise at higher concentrations. Because the topical route avoids many of the complications associated with intracavernous therapy and because of the demonstrated effects on enhancing penile arterial flow, TPH gel needs further study on larger numbers of patients to investigate clinical efficacy of the drug when it was formulated in a topical dosage form compared to intracavernous injection therapy. The present results encourage further development and optimization of the formulation in terms of efficacy and toxicity; however, many advanced therapies may also be possible in the future for the treatment of ED.

\section{Acknowledgments}

We express our gratitude to Dr Osama Sayed (Pharmaceutics Department, Faculty of Pharmacy, Beni-Suef University, BeniSuef, Egypt) and Dr Mostafa Alanwary (Dermatology and Andrology Department, Faculty of Medicine, Minia University, Minia, Egypt) for their support to accomplish this study.

\section{Disclosure}

The authors report no conflicts of interest in this work.

\section{References}

1. Wen MM, El-Kamel AH, Khalil SA. Systemic enhancement of papaverine transdermal gel for erectile dysfunction. Drug Dev Ind Pharm. 2012; 38(8):912-922.

2. Kim ED, El-rashidy R, McVary KT. Papaverine topical gel for treatment of erectile dysfunction. J Urol. 1995;153(2):361-365.
3. Montorsi F, Salonia A, Zanoni M, et al. Current status of local penile therapy. Int J Impot Res. 2002;14(1):S70-S81.

4. Gupta A, Aggarwal G, Singla S, Arora R. Transferosomes: a novel vesicular carrier for enhanced transdermal delivery of sertraline: development, characterization, and performance evaluation. Sci Pharm. 2012;80:1061-1080.

5. Fadel M, Abdelbary G, Elmenshawe SF, Eissa E. Toluidine blue loaded transferosomes for topical photodynamic therapy: formulation and characterization. Int J Res Pharm Sci. 2011;2(4):537-544.

6. Malakar J, Sen SO, Nayak AK, Sen KK. Formulation, optimization and evaluation of transferosomal gel for transdermal insulin delivery. Saudi Pharm J. 2012;20:355-363.

7. Duangjit $\mathrm{S}$, Opanasopit $\mathrm{P}$, Rojanarata $\mathrm{T}$, Ngawhirunpat T. Evaluation of meloxicam-loaded cationic transferosomes as transdermal drug delivery carriers. AAPS Pharm Sci Tech. 2013;14(1):133-140.

8. Mitkari BV, Korde SA, Mahadik KR, Kokare CR. Formulation and evaluation of topical liposomal gel for fluconazole. Indian J Pharm Educ Res. 2010;44(4):324-333.

9. Shaji J, Lal M. Preparation, optimization and evaluation of transferosomal formulation for enhanced transdermal delivery of a cox-2 inhibitor. Int J Pharm Pharm Sci. 2013;6(1):467-477.

10. Lei W, Yu C, Lin H, Zhou X. Development of tacrolimus-loaded transferosomes for deeper skin penetration enhancement and therapeutic effect improvement in vivo. AJPS. 2013;8(6):336-345.

11. Chanda H, Das P, Chakraborty R, Ghosh A. Development and evaluation of liposomes of fluconazole. J Pharm Biomed Sci. 2011; 5(27):1-9.

12. Abd-Allah FI, Dawaba HM, Ahmed AM. Preparation, characterization, and stability studies of piroxicam loaded microemulsions in topical formulations. Drug Discov Ther. 2010;4(4):267-275.

13. Muppidi K, Pumerantz AS, Wang J, Betageri G. Development and stability studies of novel liposomal vancomycin formulations. ISRN Pharm. 2012;2012:636743.

14. Wasankar SR, Faizi SM, Deshmuk AD. Formulation and development of liposomal gel for topical drug delivery system. Int J Pharm Sci Res. 2012; 3(11):4461-4474.

15. Viswaroop B, Antonisamy B, Gopalakrishnan G. Evaluating erectile dysfunction: oral sildenafil versus intracavernosal injection of papaverine. Natl Med India. 2005;18:299-301.

16. Ali MF. Topical delivery and photodynamic evaluation of a multivesicular liposomal Rose Bengal. Lasers Med Sci. 2011;26(2): 267-275.

17. Patel R, Singh SK, Singh S, Sheth NR, Gendle R. Development and characterization of curcumin loaded transferosome for transdermal delivery. J Pharm Sci Res. 2009;1(4):71-80.

18. Abdulridha RS, Hashim HA, Kadhim AH, Dakhil MM, Sajjad AO. Effect of method of preparation on physical properties of ciprofloxacin HCL elastic liposomes intended to be utilized in treatment of acne vulgaris. Int J Res Ayurveda Pharm. 2013;4(5):742-746.

19. Shaji J, Lal M. Novel double loaded transferosomes: evidence of superior anti-inflammatory efficacy-a comparative study. Int J Curr Pharm Res. 2014;6(2):16-25.

20. Mokhtar M, Sammour OA, Hammad MA, Megrab NA. Effect of some formulation parameters on flurbiprofen encapsulation and release rates of niosomes prepared from proniosomes. Int J Pharm. 2008;361: 104-111.

21. Panwar P, Pandey B, Lakhera PC, Singh KP. Preparation, characterization, and in vitro release study of albendazole-encapsulated nanosize liposomes. Int J Nanomedicine. 2010;5:101-108.

22. Nounou MM, El-khordagui LK, Khalafallah NA, Khalil SA. In vitro release of hydrophilic and hydrophobic drugs from liposomal dispersions and gels. Acta Pharm. 2006;56:311-324.

23. Naga Sravan Kumar Varma V, Maheshwari PV, Navya M, Reddy SC, Shivakumar HG, Gowda DV. Calcipotriol delivery into the skin as emulgel for effective permeation. Saudi Pharm J. 2014;22(6):591-599.

24. Ghanbarzadeh S, Arami S. Enhanced transdermal delivery of diclofenac sodium via conventional liposomes, ethosomes, and transferosomes. Biomed Res Int. 2013;2013:616810. 
25. Prajapati ST, Patel CG, Patel CN. Transferosomes: a vesicular carrier system for transdermal drug delivery. AJBPR. 2011;2(1):507-524.

26. Thorve VS, Kshirsagar AD, Vyawahare NS, Joshi VS, Ingale KG, Mohite RJ. Diabetes-induced erectile dysfunction: epidemiology, pathophysiology and management. J Diabetes Complications. 2011;25: 129-136.

27. Doumas M, Douma S. The effect of antihypertensive drugs on erectile function: a proposed management algorithm. J Clin Hypertens. 2006; 8(5):359-363.
28. Copel L, Katz R, Blachar A, Sosna J, Sheiman RG. Clinical and duplex US assessment of effects of sildenafil on cavernosal arteries of the penis: comparison with intracavernosal injection of vasoactive agents - initial experience. Radiology. 2005;237(3):986-991.

29. Yang Y, Hu JL, Ma Y, et al. Pharmaco-induced erections for penile color-duplex ultrasound: oral PDE5 inhibitors or intracavernosal injection? Int J Impot Res. 2012;24(5):191-195.

\section{Publish your work in this journal}

Drug Design, Development and Therapy is an international, peerreviewed open-access journal that spans the spectrum of drug design and development through to clinical applications. Clinical outcomes, patient safety, and programs for the development and effective, safe, and sustained use of medicines are a feature of the journal, which has also been accepted for indexing on PubMed Central. The manuscript management system is completely online and includes a very quick and fair peer-review system, which is all easy to use. Visit http://www.dovepress.com/testimonials.php to read real quotes from published authors.

Submit your manuscript here: http://www.dovepress.com/drug-design-development-and-therapy-journal 